progressive improvement, that of a large number of them being regarded as "satisfactory." The mortality among single patients is considerably less than among the inmates of asylums; whereat the Commissioners are not surprised, "considering the amount of active disease in such establishments." But that it should be so much below the rate occurring in lunatic wards of poor-houses appears to them remarkable, " especially when it is taken into account that the patients in such wards are, for the most part, like those in private dwellings, idiots and dements, and that, as a rule, the physical wants of the former are more amply supplied." It is conjectured that the manner of living in private dwellings, involving generally greater freedom and variety, more than counterbalances the advantages of better diet, clothing, bedding, and housing, and of greater cleanliness.

Dr. Mitchell has some excellent remarks on the effects of removal to an asylum of patients long secluded, restrained, or grossly neglected; and he adduces the details of twenty-one of the worst of such cases ever brought under the notice of the Board in support of the position that nothing bas occurred in reference to this class of patients to raise a misgiving as to whether the course adopted by the Board in removing them to an asylum was the proper and humane one. That death not unfrequently takes place within a short time after the admission of such cases into asylums is a fact which has sometimes been brought forward as a reason for opposing the Buard's order to remove a patient; but Dr. Mitchell shows that such an objection is untenable when the circumstances of each case are properly considered, and even if the change does sometimes result unfavourably, he does not see how that can be guarded against, "unless, indeed, it were by a treatment more or less influenced by the principles which direct the treatment of persons long exposed to cold and bunger, and involving among other things some restriction of the dietary for a time after admission."

To remove a misapprehension which appears to exist in regard to the nature, antecedents, and distribution of pauper lunatics classed as "single patients" in Scotland, as well as in reference to the extent of the supervision exercised over them by the Board of Lunacy, and the applicability or nonapplicability of a similar system in England, Dr. Paterson remarks that such single patients are not recruited by the practice of drafting them out of asylums into private houses, under the care of persons wholly unconnected with them. The greater number of single patients ( 72 per cent.) are living with their own families, or near relatives, and only 17 per cent. of the whole have ever been in asylums at all; the great majority have simply been allowed to remain where they were found.

"The real advantage," says Dr. Paterson, "which the Scotch system can lay claim to in its mode of dealing with single patients...... appears to me to consist not so much in the fact of the residence of a certain proportion of pauper lunatics with their own families or with strangers, as in the necessity for the sanction of the Board of Lunacy being given in each case before such residence can be permitted, and in the visits which it is the duty of parochial medical officers and inspectors of poor to pay to the patients at regular periods being supplemented by those of accredited representatives of the Board of Lunacy, who are charged to inquire into the suitableness of the case for domestic care, and into the sufficiency of the guardianship, allowances, clothing, and general accommodation, and on whose unfavourable report the sanction may be withdrawn and the patients sent to an asylum."

From the Irish Lunacy Report it appears that on the 31 st of December, 1867, the insane in Ireland were distributed as follows: 5212 in public and 626 in private asylums; 334 in gaols; 2705 in poor-houses; 209 in criminal and state asylums; making altogetber 9086 registered lunatics, which, in addition to 6564 lunatics at large, make a grand total of 15,650 insane. The registered lunatics show an increase of 124 in the year. In the district asylums, a marked im. provement appears in the percentage of recoveries on the number admitted, the ratio last year being $41 \mathrm{~s}$, against $37 \cdot 5$ in the previous year; at the same time, the death-rate has considerably increased, notwithstanding the satisfactory sanitary condition of the asylums, the augmented mortality being in a great measure attributable to the unprecedented severity of the weather in the spring of last year. The Irish Commissioners report that the condition of the Junatic inmates of poor-houses inspected by them was, on the whole, satisfactory; they notice also the fact that, whlle the mortality in private licensed houses is much less than in public asylums, the proportion of cures is smaller also. An important change has been made in the law relating to the detention of lunatics in gaols, by the repeal of the clauses previously in force empowering magistrates to commit lunatics alleged to be "dangerous" to prison: by an Act (30 and 31 Vict., c. 118) passed last August, it is provided that thenceforth such lunatics shall be committed direct to the asylum of the county or district in which they shall have been apprehended. The Commissioners. look upon this as a "salutary reform," expressing at the same time a hope that magistrates will exercise their new powers discreetly, and commit none but really "dangerous" lunatics, leaving the other classes of insane to find their way into the asylums through the usual channels.

\section{ENTERIO FEVER.}

\section{To the Editor of THE LANCET.}

SIR,-Dr. Glover's remarks on "The Season and Disease" in your impression of the 4 th instant have suggested to me the idea of sending you a few lines on a similar subject.

Enteric fever is known to be most common in autumn and early winter. Instances of its unusual prevalence at other seasons are doubtless by no means rare; but they generally occur in towns or in localities in which some accidental contamination of the atmosphere or water is found in explanation of the existence of the fever at that time.

It is in rural districts that its prevalence in autumn is most marked, and it has generally been observed that the disease most prevails after an unusually hot and dry summer, such as the present. In these districts there are found sanitary conditions which now exist in towns to a very limited extent. The drains are on the surface, and the water is got from wells. Most outbreaks of enteric fever in such localities are due to the contamination of the water by sewage matter filtering through the soil into the wells; and the disease is much increased by the further pollution of the water by materials derived from the stools of those first affected. The probable explanation of the greater prevalence of the fever after a long track of such weather as we are now experiencing is that "the dry season leads to the retention in the soil of sewage impurities which a succeeding wet season causes to be conveyed into the wells, and directly as the extent to which these conditions of the seasons prevail is the likelihood of an outbreak of enteric fever in the latter of the two."* We may, therefore, expect that if (as is most likely) this hot dry summer is succeeded by a wet autumn, we shall hear of the existence of a more than usual amount of enteric fever and diarrhœa (choleraic or not) in localities whose sanitary condition is such as I have indicated.

If the attention of practitioners and others resident in such localities were directed to the matter, many outbreaks might be curtailed, and much permanent good done by opening the eyes of the inhabitants to the existence of an evil which they would never discover for themselves. I know of no more suitable or efficacious means of attaining this end than a few warning words from THE LANCET. Hexce my reason for troubling you now whilst the dry weather prevails. I am, Sir, your obedient servant,

$\begin{array}{ll}\text { Cupar, Fife, July 14th, Is63. } & \text { T. J. MACLAGAN, M.D. }\end{array}$

* I quote from a paper published in the Edinburgh Medical Journal for Octrib. $r, 1867$, i. which I gave in account of an outbreak of enteric ferer which was satisfactorily explained in the manner indicated.

SUNSTROKE.- Several cases of sunstroke have occurred in various parts of the country. 